Захаров В.В., Вахнина Н.В.

Кафедра нервных болезней и нейрохирургии ФГАОУ ВО «Первый Московский государственный медицинский университет им. И.М. Сеченова (Сеченовский университет)» Минздрава России, Москва, Россия

119021, Москва, ул. Россолимо, 11, стр. 1

\title{
Достижения нейрометаболической терапии
}

\begin{abstract}
Актовегин - производное крови телят, которое содержит более 200 биологически активных соединений. В экспериментальных условиях показано, что Актовегин уменьшает нейротоксический эффект амилоида, нейтрализует активные формы кислорода, нормализует эндотелиальную функцию сосудов небольшого калибра. На модели нейробластомы показано, ито препарат не стимулирует опухолевый рост. Клинический опыт использования Актовегина свидетельствует о его несомненной эффективности при умеренных когнитивных нарушениях сосудистого генеза и при хронической симметричной дистальной диабетической полиневропатии, а также в качестве дополнительной терапии деменции первично-дегенеративной и сосудистой природы. В настоящее время активно изучается клиническая эффективность Актовегина при хронических облитерирующих заболеваниях артерий нижних конечностей.
\end{abstract}

Ключевые слова: Актовегин; сосудистые когнитивные нарушения; полиневропатия.

Контакты: Владимир Владимирович Захаров; zakharovenator@gmail.com

Для ссылки: Захаров ВВ, Вахнина НВ. Достижения нейрометаболической терапии. Неврология, нейропсихиатрия, психосоматика. 2019;11(3):129-136.

\section{Advances in neurometabolic therapy}

Zakharov V.V., Vakhnina N.V.

Department of Nervous System Diseases and Neurosurgery, I.M. Sechenov First Moscow State Medical University (Sechenov University), Ministry of Health of Russia, Moscow, Russia

11, Rossolimo St., Build 1, Moscow 119021

Actovegin is a calf blood extract that contains more than 200 biologically active compounds. Experiments have shown that Actovegin reduces the neurotoxic effect of amyloid, neutralizes reactive oxygen species, and normalizes the endothelial function of small vessels. The drug has not been shown to stimulate tumor growth in the neuroblastoma model. Clinical experience with Actovegin suggests that the drug has an undoubted efficacy in treating moderate vascular cognitive impairment and chronic distal symmetric diabetic polyneuropathy and that it is used as additional therapy for primary degenerative and vascular dementia. The clinical efficacy of Actovegin in chronic obliterating diseases of the lowerlimb arteries is being actively studied now.

Keywords: Actovegin; vascular cognitive impairment; polyneuropathy.

Contact: Vladimir Vladimirovich Zakharov; zakharovenator@gmail.com

For reference: Zakharov $V V$, Vakhnina $N V$. Advances in neurometabolic therapy. Nevrologiya, neiropsikhiatriya, psikhosomatika = Neurology, Neuropsychiatry, Psychosomatics. 2019;11(3):129-136.

DOI: 10.14412/2074-2711-2019-3-129-136

Нейрометаболическая терапия имеет широкие показания при самых разнообразных заболеваниях нервной системы. Целью нейрометаболической терапии является, во-первых, создание метаболической защиты нейронов от ишемии, гипоксии и других повреждающих воздействий (нейропротекция). Во-вторых, на фоне оптимизации церебрального метаболизма происходит активация процессоров нейрональной пластичности и нейрорепарации (нейротрофический эффект). Именно эти процессы лежат в основе функционального восстановления после инсульта, черепно-мозговой травмы или иного острого локального или диффузного поражения головного мозга. Поэтому нейрометаболическая терапия способствует уменьшению степени и темпа повреждения нервной системы при различных патологических состояниях и мобилизует внутренние резервы головного мозга для преодоления последствий таких повреждений. Важным клиническим эффектом нейрометаболической терапии является улучшение когнитивных функций у пациен- тов с различными сосудистыми и нейродегенеративными церебральными заболеваниями. В настоящее время в нашей стране нейрометаболическая терапия используется в качестве основного лечения когнитивных нарушений (KH) у пациентов с легкими и умеренными (недементными) расстройствами высших мозговых функций, в восстановительном периоде инсульта, черепно-мозговой травмы, иного острого локального или диффузного повреждения нервной системы.

Актовегин представляет собой классический нейрометаболический препарат, который хорошо зарекомендовал себя у российских неврологов и врачей других специальностей в результате 35-летнего успешного применения в клинической практике в нашей стране.

\section{Состав Антовегина}

Актовегин получают из крови телят методом ультрафильтрации. В процессе производства Актовегина из первоначального сырья удаляют все молекулы массой >5000 Да, 
включая любые белки, эндотоксины и антигены. Состав Актовегина неоднократно уточнялся с помощью современных высокотехнологичных методик, таких как газовая и жидкостная хроматография в сочетании с масс-спектроскопией. Установлено, что в состав лекарственного средства входит более 200 биологически активных соединений, в том числе незаменимые аминокислоты, биогенные амины, полиамины, сфинголипиды, эйкозаноиды, гексозы, лактат, сукцинат, холин, витамины, аденозинмонофосфат, ацетилкарнитины, фосфолипиды и др. Перечисленные вещества оказывают многомодальное положительное воздействие на нейрональные мембраны и внутриклеточный метаболизм, включая процессы синтеза белка и аденозинтрифосфата, а также на функцию эндотелия церебральных микрососудов. Важно подчеркнуть, что Актовегин полностью лишен белковых молекул, поэтому практически не вызывает аллергических реакций и абсолютно безопасен в отношении трансмиссивных белковых заболеваний. После завершения процесса ультрафильтрации отсутствие белка в полученном препарате обязательно верифицируется с помощью электрофореза в SDS-полиакриламидном геле. Все молекулы, содержащиеся в Актовегине, присутствуют в человеческом организме в норме и представляют собой естественные метаболиты, поэтому Актовегин оказывает плейотропное действие на нейрональный метаболизм, изменяя его исключительно в пределах физиологического гомеостаза [1-3].

\section{Механизмы действия Аитовегина}

В многочисленных доклинических исследованиях in vitro и in vivo показано, что благоприятное нейропротективное, нейротрофическое и когнитивное воздействие Актовегина связано со следующими механизмами:

- активация внутриклеточных окислительных процессов, что приводит к увеличению утилизации кислорода без роста потребности в нем, повышает синтез аденозинтрифосфата, что в конечном итоге повышает выживаемость клеток в условиях ишемии и гипоксии (антигипоксический эффект) [4-7];

- активация трансмембранного транспорта глюкозы внутрь нейронов и повышение утилизации глюкозы - инсулиноподобный эффект без воздействия на рецепторы к инсулину; предполагается, что в основе данного эффекта лежит усиление высвобождения инозитололигосахаридов из клеток гепатоцитов [8-14];

- уменьшение содержания активных форм кислорода, ингибирование процессов перекисного окисления липидов (антиоксидантный эффект) [15, 16];

- стимуляция иммунокомпетентных клеток, активация факторов, регулирующих процессы тканевого воспаления и апоптоза (NF-кB) [2];

- нормализация функции эндотелия микроциркуляторного русла, увеличение кровотока по капиллярам (антиишемический эффект) [17].

Нейропротективный и нейротрофический эффекты Актовегина были подробно изучены в работе M. Elmlinger и соавт. [16] на модели эмбриональных нейронов гиппокампа крыс. Нейроны были взяты у 18-дневных эмбрионов, культивированы стандартным образом и наблюдались в течение 10 дней на фоне применения различных доз Актовегина или без применения исследуемого препарата. После 10 дней инкубации число живых клеток оказалось достоверно боль- шим (в 2,4 раза) на фоне использования Актовегина, чем в контрольной культуре нейронов. Этот эффект был дозозависимым и прослеживался начиная с дозы 10 мкг/мл. Одновременно отмечались увеличение плотности дендритной сети в обработанной лекарством культуре по сравнению с необработанной и достоверное превосходство обработанной культуры по числу активных синапсов (в 3,6 раза; $\mathrm{p}<0,001)$. Не было получено, однако, существенного роста аксонов после применения Актовегина. Также было показано, что Актовегин дозозависимым образом защищает нейроны от повреждающего воздействия амилоидного белка и процессов перекисного окисления липидов. Как известно, отложение в паренхиме головного мозга патологического амилоидного белка рассматривается в настоящее время в качестве первого этапа патогенеза самого распространенного нейродегенеративного заболевания - болезни Альцгеймера. Церебральный амилоидный белок реализует свое нейротоксическое действие через активацию тканевого воспаления, перекисное окисление липидов, глутаматергическую эксайтотоксичность и другие механизмы. В цитируемой экспериментальной работе основной фрагмент амилоидного белка добавлялся к эмбриональным нейронам гиппокампа крыс, обработанным в разных концентрациях Актовегином или нативных. Было выявлено, что вызванная амилоидным белком А $\beta 25-35$ индукция апоптоза в значительной степени нивелируется при использовании терапевтических доз Актовегина. В другой экспериментальной модели апоптоз индуцировали добавлением к клеточной культуре тетрабутилгидропероксида - вещества с мощным прооксидантным эффектом. Однако в культурах, обработанных терапевтическими дозами Актовегина, содержание активных форм кислорода было достоверно $(\mathrm{p}<0,001)$ меньшим, чем в отсутствие лекарственного средства [15].

По экспериментальным данным, Актовегин не только обладает нейропротективным эффектом, но и оказывает положительное влияние на эндотелий сосудистой стенки, В исследовании А.A. Fedorovich и соавт. [17] 28 условно здоровым добровольцам внутривенно вводилось 1 или 2 г лекарственного вещества, после чего методом лазерной капилляроскопии оценивали изменения периферического кровотока. Было показано, что через 2-6 ч после введения Актовегина фиксируется значительное увеличение кровенаполнения в периферических метаартериолах и капилляpax, которое достоверно превосходит аналогичные изменения после введения физиологического раствора (рис. 1). Анализ колебаний перфузии крови по микроциркуляторному руслу свидетельствовал, что реактивная периферическая вазодилатация после введения Актовегина развивалась главным образом за счет изменения реактивности эндотелия микрососудов. Одновременно было зафиксировано некоторое положительное влияние на мышечную оболочку микрососудов. Полученные результаты позволяют считать Актовегин средством патогенетической терапии сосудистого поражения головного мозга при артериальной гипертензии (АГ), сахарном диабете (СД) и других заболеваниях, где эндотелиальная дисфункция играет важную роль [17].

О положительном когнитивном эффекте Актовегина сообщают S. Meilin и соавт. [18]. У экспериментальных животных вызывали транзиторную глобальную ишемию головного мозга, а затем оценивали их способность к пространственной ориентировке в заданиях с водным лабирин- 

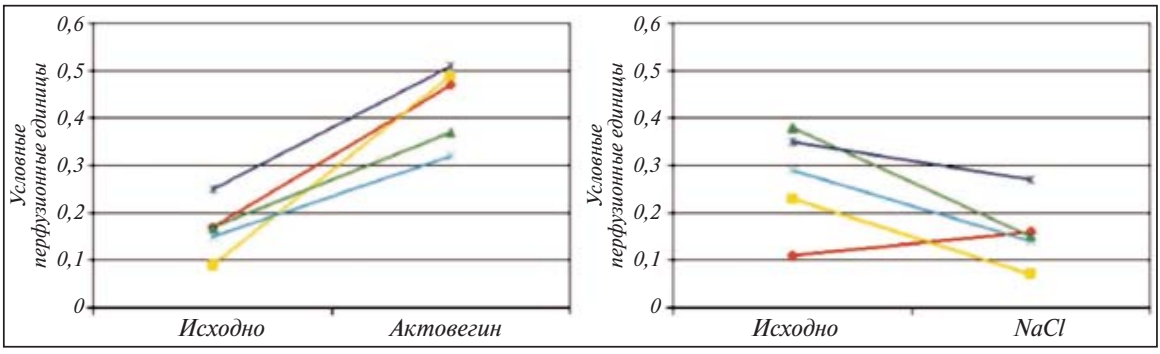

Рис. 1. Динамика максимальных значений амплитуды эндотелиального ритма в процессе острого фармакологического теста у 5 испытуемых после введения Актовегина и физиологического раствора ( $\mathrm{NaCl}$ ) [17]

\section{- Уменьшение выражсениости симптомов деменци}

- Повышение способности к самообслуживанию
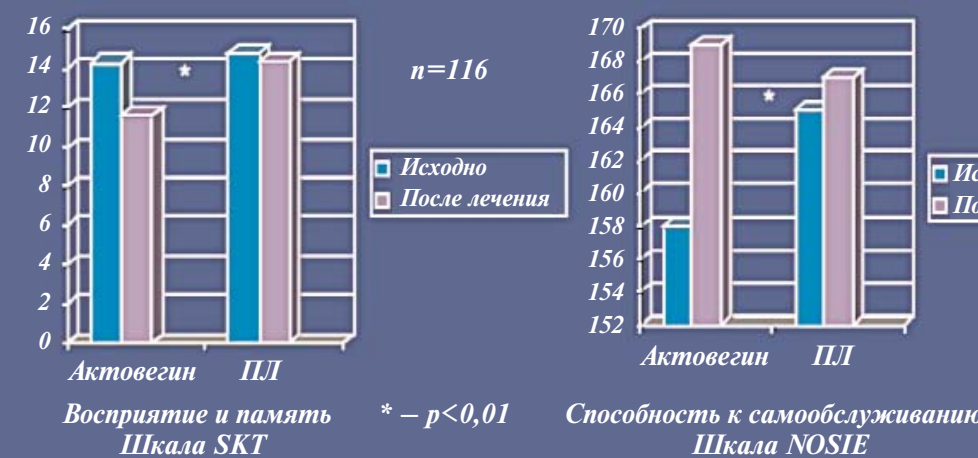

Шкала SKT

Актовегии 500 мл 20\% р-ра в/в 3 раза в неделю в течение 4 нед

Рис. 2. Опыт применения Актовегина у пациентов с болезнью Альцгеймера и сосудистой деменцией [19]

том. Было показано, что лечение Актовегином способствует более быстрому нахождению экспериментальным животным выхода из лабиринта. При патоморфологическом исследовании авторы обнаружили достоверно большую выживаемость нейронов гиппокампов обоих полушарий на фоне лечения Актовегином по сравнению с контрольной группой животных. Увеличение выживаемости нейронов на фоне Актовегина было продемонстрировано и во многих других экспериментальных моделях церебральной ишемии.

Помимо нейротропных эффектов Актовегина, многочисленные исследования свидетельствуют о способности данного препарата ускорять заживление ран и уменьшать выраженность радиационного повреждения периферических тканей. Есть отдельные сообщения о снижении на фоне применения Актовегина риска тромбозов, благоприятном влиянии препарата на сердечный выброс и функцию кардиомиоцитов [1, 2].

\section{Клинические исследования Актовегина}

Актовегин имеет доверительную доказательную базу клинической эффективности при деменциях различной этиологии, синдроме умеренных когнитивных нарушений (УКН) и диабетической полиневропатии.

В работе W.M. Herrmann и соавт. [19] Актовегин применяли в смешанной группе пациентов с деменцией, в которую вошли как лица, страдающие болезнью Альцгеймера, так и пациенты с выраженными стадиями сосудистого поражения головного мозга (рис. 2). Многомодальный плейотропный эффект изучаемого препарата делает возможным и обоснованным подобный дизайн исследования, так как Актовегин воздействует на патогенетические механизмы, общие для обеих распространенных форм деменции. Исследование было выполнено по двойному слепому рандомизированному проспективному методу. Пациенты $(\mathrm{n}=120)$ получали Актовегин в дозе 2000 мг в виде внутривенных капельных вливаний трижды в неделю в течение 4 нед или аналогичное по внешнему виду плацебо (ПЛ). Для оценки эффективности использовались как нейропсихологические методики (принятый в Германии так называемый «короткий синдромный тест»), так и психометрические шкалы для оценки эмоционально-поведенческой сферы и опросники, которые позволяют оценить степень самостоятельности пациентов, а следовательно, клиническую значимость полученных результатов. В итоге было выявлено, что пациенты, получавшие Актовегин, после лечения достоверно превосходили больных из группы ПЛ как по когнитивным, так и по поведенческим показателям и параметрам самостоятельности в повседневной жизни. Различия достигали статистической значимости как при анализе общей популяции, так и в группах первично-дегенеративной и сосудистой деменции отдельно.

В сходном по дизайну исследовании S. Kanowsky и соавт. [20] 60 пациентов с синдромом деменции различной этиологии получали внутривенные вливания $20 \%$ раствора Актовегина в дозе 250 мл ежедневно в течение 4 нед или ПЛ. К окончанию терапии пациенты, получавшие действующий препарат, достоверно превосходили группу ПЛ как по нейропсихологическим тестам, так и по эмоционально-поведенческим показателям и общим клиническим шкалам.

После внедрения в клиническую практику ацетилхолинергических препаратов и мемантина актовегин используется как дополнительное лечение первично-дегенеративной или сосудистой деменции. Обычно он назначается пациентам, уже стабилизированным благодаря применению так называемой базисной терапии для усиления эффективности антидементных препаратов. Он может использоваться также в качестве альтернативной терапии при наличии противопоказаний к приему ингибиторов ацетилхолинэстеразы или мемантина.

Однако с учетом нейропротективного эффекта Актовегина наибольший интерес врачей и исследователей вызывает использование данного препарата до развития выраженных КН. Следует отметить, что международным научным сообществом до сих пор не разработан общепринятый протокол ведения пациентов с легкими или умеренными КН, поэтому изучение нейропротективных препаратов на этой стадии особенно актуально. 
В наиболее крупном рандомизированном контролируемом исследовании эффективности Актовегина при синдроме УKH - ARTEMIDA [21] участвовали пациенты с постинсультным вариантом сосудистых КН легкой и умеренной выраженности. У пациентов в остром периоде нетяжелого ишемического инсульта при условии ясного сознания проводилось нейропсихологическое исследование. Если у пациента выявлялись легкие или умеренные КН, он был рандомизирован. Часть пациентов получали исследуемый препарат вначале в виде внутривенных вливаний (2000 мг ежедневно во время нахождения в стационаре, но не более 21 вливания), а затем перорально по 400 мг 3 раза в день в течение 6 мес. Остальные пациенты получали аналогичное по внешнему виду ПЛ. Всего в исследовании приняли участие более 500 пациентов с синдромом сосудистых УКН. Оценка эффективности проводимой терапии осуществлялась на 21й день, через 3, 6 и 12 мес лечения. Превосходство Актовегина над ПЛ было зафиксировано уже через 3 мес терапии и сохранялось в течение всего срока наблюдения (1 год; рис. 3). Представляет интерес тот факт, что последние 6 мес на-

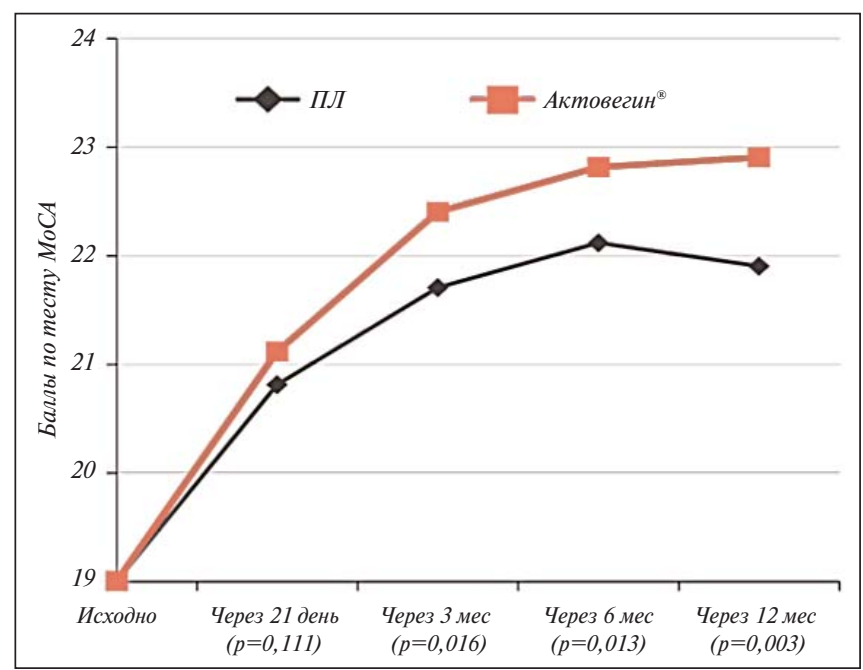

Рис. 3. Динамика результата МоСА-теста на фоне терапии Актовегином у пациентов с синдромом УКН сосудистой природы [21]

блюдения пациенты не получали терапию исследуемым препаратом. Тем не менее величина терапевтического эффекта продолжала возрастать. Вероятно, в основе отсроченного эффекта препарата лежит его влияние на ключевые нейротрофические факторы и их отсроченное активирующее воздействие на церебральные репаративные процессы. Важно подчеркнуть, что Актовегин является единственным на сегодняшний день препаратом с доказанной в рандомизированном исследовании эффективностью при сосудистых УКН.

Интерес к применению Актовегина при КН, не достигающих выраженности деменции, присутствует и у европейских коллег. В одной работе [22] применяли Актовегин в двойном слепом исследовании у пациентов с синдромом хронической ишемии головного мозга. Пациенты были рандомизированы на три группы по 40 человек: 1-я группа получала Актовегин по 400 мг 3 раза в день, 2-я группа - Актовегин по 600 мг 3 раза в день и 3-я группа - ПЛ. Длительность лечения составила 3 мес. Эффективность терапии оценивали с помощью большого числа нейропсихологических методик, включая тесты на память, внимание, решение задач, темп познавательной деятельности и т. д. В результате было показано, что к окончанию срока терапии пациенты, получавшие Актовегин, имеют достоверное преимущество над ПЛ по большинству использованных в работе методик. При этом величина эффекта существенно нарастала к третьему визиту (через 3 мес лечения) по сравнению с предыдущим лечением. Это говорит о целесообразности более продолжительных курсов лекарственной терапии. В то же время не получено различий между сравниваемыми режимами дозирования Актовегина: увеличение дозы до 600 мг 3 раза в день не давало никаких дополнительных преимуществ по сравнению с дозой 400 мг 3 раза в день.

W.D. Oswald и соавт. [23] изучали влияние Актовегина на темп познавательного процесса. Это очень важный показатель, который отражает функционирование неспецифических срединных стволово-подкорковых структур головного мозга и коррелирует с другими показателями внимания. Следует отметить, что снижение темпа познавательного процесса (брадифрения) является основным и самым ранним признаком подкоркового типа КН, к которому относятся в том числе сосудистые КН. Пациенты с формальным диагнозом «психоорганический синдром» $(n=128)$ были рандомизированы на две группы и получали лечение в течение 3 мес. Пациенты терапевтической группы получали Актовегин перорально в стандартной дозировке (400 мг 3 раза в день). В результате заранее определенная первичная конечная точка была достигнута: авторы показали, что лечение Актовегином способствует достоверному регрессу брадифрении.

В нескольких ранних зарубежных работах [24-26] отмечено свойство Актовегина позитивно влиять на электрофизиологические показатели пожилых людей с признаками возрастного когнитивного снижения. Наблюдались регресс относительной мощности медленноволновой биоэлектрической активности головного мозга и уменьшение латентного периода когнитивного вызванного потенциала Р300. Это соответствует общепринятому представлению о желательном профиле действия ноотропных препаратов и соотносится с приведенными выше клиническими данными.

В основе положительного когнитивного эффекта Актовегина, вероятно, лежит его влияние на эндотелиальную дисфункцию и ремоделирование капиллярного русла, о чем уже говорилось ранее. В работе А.А. Федоровича и Г.Н. Соболевой [27] метод лазерной капилляроскопии ногтевого ложа проводился пациентам с АГ до и после курсового лечения Актовегином. Пациенты с АГ $(\mathrm{n}=40)$ были разделены на две группы: в обеих группах уже на момент включения в исследование был достигнут адекватный контроль основного заболевания. Однако увеличение кровотока по микроциркуляторному руслу наблюдалось только у тех пациентов, которым было проведено курсовое лечение Актовегином. Улучшение микроциркуляции сопровождалось достоверной положительной динамикой в когнитивной сфере, в первую очередь по результатам тестов на внимание и темп познавательной деятельности. Таким образом, только антигипертензивной терапии, вероятно, недостаточно для нивелирования эндотелиальной дисфункции. Чтобы получить более полный клинический эффект, необходимо сочетать антигипертензивную терапию с патогенетическим нейро- 
метаболическим лечением, и в качестве препарата выбора можно рекомендовать Актовегин.

Об улучшении когнитивных функций на фоне АГ сообщают также некоторые другие авторы [28, 29]. Мы наблюдали достоверное улучшение когнитивных функций у пациентов с недементными КН на фоне СД, причем это улучшение было достоверным и клинически значимым как в группе относительно «чистой» диабетической энцефалопатии, где все остальные факторы риска церебральной патологии были минимизированы, так и при сочетании СД с АГ, атеросклерозом и другими сосудистыми факторами риска [30].

Механизм действия Актовегина позволяет использовать данный препарат не только при церебральной патологии, но и при заболеваниях периферической нервной системы. На сегодняшний день серьезной неврологической и эндокринологической проблемой остается хроническая дистальная симметричная диабетическая полиневропатия. Следует сказать, что современные международные рекомендации ограничиваются лишь достижением метаболического контроля и симптоматическим лечением болевого синдрома, если последний имеет место. Однако клиническая практика свидетельствует, что достижение адекватного метаболического контроля является обязательным, но недостаточным. Как и при АГ, контроль основного заболевания сам по себе не приводит к обратному развитию имеющихся неврологических осложнений. Необходимо также проведение патогенетической терапии.

Многие экспериментальные исследования свидетельствуют о том, что хроническая симметричная дистальная полиневропатия развивается по патогенетическим механизмам, сходным с теми, которые вызывают поражение головного мозга при микроангиопатии. Установлено, что ключевую роль в развитии данного неврологического механизма играют свободнорадикальное повреждение эндотелия сосу-
Наиболее масштабное изучение эффективности нейрометаболической терапии при диабетической полиневропатии проведено в исследовании D. Zigler и соавт. [31]. В нем участвовало 567 пациентов с СД 2-го типа и хронической дистальной симметричной полиневропатией. Пациенты были рандомизированы на две группы: основная группа получала Актовегин в дозе 2000 мг в виде ежедневных внутривенных вливаний, общим числом 20. В дальнейшем эти пациенты получали исследуемый препарат перорально по 400 мг 3 раза в день в течение 6 мес. Вторая группа пациентов получала аналогичное по внешнему виду и форме введения ПЛ. Эффективность терапии оценивали по общепринятым для оценки тяжести полиневропатии методикам: общей шкале субъективных симптомов (англ. Total Symptom Score), объективной шкале Neuropathy impairment score low limbs (NIS-LL) и изменению порога вибрационной чувствительности. Также оценивали качество жизни пациента. В результате исследования группа Актовегина достоверно превосходила ПЛ по шкале субъективных симптомов. Регрессировали «стреляющие», жгучие боли и парестезии, уменьшилось ощущение онемения. Объективно отмечалось достоверное понижение порога вибрационной чувствительности. Не было достигнуто статистической значимости различий по общему показателю шкалы NIS-LL, но по отдельным, очень важным для пациента показателям (например, сенсорные расстройства) пациенты группы Актовегина также достоверно превосходили получивших ПЛ. В итоге наблюдалось достоверное преимущество группы Актовегина по показателю качества жизни. Таким образом, Актовегин в настоящее время может с полным основанием расцениваться как эффективный препарат для патогенетического лечения самого частого неврологического осложнения СД хронической симметричной дистальной полиневропатии (см. таблицу).

Изменение ключевых клинических характеристикна фоне использования Актовегина у пациентов с диабетической полиневропатией [31]

\begin{tabular}{|c|c|c|c|c|}
\hline Показатель & Актовегин (n=276) & ПЛ (n=280) & $\begin{array}{l}\text { Разница } \\
\text { (95\% доверительный } \\
\text { интервал) }\end{array}$ & $\mathbf{p}$ \\
\hline Оценка по шкале TSS & $-5,5 \pm 2,6$ & $-4,7 \pm 2,9$ & $-0,86$ (от $-1,22$ до $-0,50)$ & $<0,0001$ \\
\hline «Стреляющая» боль & $-1,2 \pm 1,2$ & $-1,0 \pm 1,2$ & $-0,20$ (от $-0,32$ до $-0,08)$ & 0,0015 \\
\hline Жгучая боль & $-1,5 \pm 1,1$ & $-1,3 \pm 1,2$ & $-0,26$ (от $-0,38$ до $-0,14)$ & $<0,0001$ \\
\hline Онемение & $-1,4 \pm 1,1$ & $-1,2 \pm 1,1$ & $-0,24$ (от $-0,38$ до $-0,10)$ & 0,0010 \\
\hline Порог вибрационной чувствительности & $-3,6 \pm 4,5$ & $-2,9 \pm 4,7$ & -5 (от -9 до -1$)$ & 0,017 \\
\hline Сенсорная функция по шкале NIS-LL & $-2,1 \pm 2,1$ & $1,7 \pm 2,1$ & $-0,38$ (от $-0,64$ до $-0,12)$ & 0,0045 \\
\hline
\end{tabular}

дов микроциркуляторного русла, эндотелиальная дисфункция с формированием патологического шунтирования крови в обход капилляров и хроническая ишемия. Поэтому предпринимаются попытки использования препаратов с антиоксидантным и эндотелий-протективным эффектом при диабетической полиневропатии.
Эффективность Актовегина при диабетической полиневропатии была показана и в ряде других, менее масштабных, исследований. При этом в работе Ф.Э. Моргоевой и соавт. [32] клиническое улучшение сопровождалось снижением содержания в крови малонового диальдегида, который является одним из основных показателей актив- 
ности оксидантного стресса. Поэтому можно сделать вывод, что в основе положительного эффекта Актовегина при диабетической полиневропатии лежит в том числе его благоприятное влияние на процессы перекисного окисления липидов.

При экстраневральной патологии имеется положительный опыт использования Актовегина при хронических облитерирующих заболеваниях артерий нижних конечностей (ХОЗАНК) и осложненных формах хронической венозной недостаточности (ХВН). В ряде отечественных и зарубежных рандомизированных плацебоконтролируемых либо с активным контролем исследований с небольшой выборкой было показано, что препарат увеличивал дистанцию безболевой ходьбы у пациентов с ХОЗАНК стадии IIB, а также сокращал сроки лечения венозных трофических язв на всех стадиях течения раневого процесса, способствовал более быстрому купированию отечно-болевого синдрома [33-38]. В настоящее время проходит крупное международное многоцентровое рандомизированное плацебоконтролируемое исследование, в которое планируется включить 366 пациентов с ХОЗАНК ІІВ стадии из России и ряда стран СНГ [39].

Интересны также аспекты применения Актовегина в спортивной медицине. В последние годы в неспециализированной прессе были опубликованы противоречивые дискуссии сторонников и противников применения препарата в спорте высоких достижений. Как известно, актовегин увеличивает поступление кислорода и глюкозы, усиливает клеточный метаболизм, а в недавнем исследовании in vitro было продемонстрировано увеличение окислительного фосфорилирования в митохондриях мышечных волокон с нарушенной проницаемостью базальной мембраны у человека (полученных у нетренированных лиц с избыточной массой тела) при острой экспозиции препарата [40]. Эти данные стали основой для множества спекуляций, базирующихся на несистематических наблюдениях, что Актовегин может улучшать физические характеристики спортсменов, а также, вероятно, содержит компоненты, обладающие анаболическим действием [41]. Однако при тестировании препарата Актовегин в антидопинговых лабораториях гормонов роста или запрещенных гормонов при ультрафильтрации молекул с массой до 6000 Да обнаружено не было. На сегодняшний день, в соответствии со «Списком запрещенных препаратов и методов» WADA, Международного олимпийского комитета, Национального олимпийского комитета Германии и многих других национальных антидопинговых агентств, Актовегин не запрещен для потребления спортсменами в период соревнований или вне его [42]. Результаты последнего аналитического исследования F.X. Reichel и coавт. [43] продемонстрировали, что Актовегин содержит крайне низкие концентрации половых анаболических гормонов (тестостерона и кортизола); вместе с тем содержание ряда ингредиентов было значительно выше, чем в человеческой сыворотке. Помимо этого, было обнаружено значительное увеличение миозина в мышечных клетках С2C12, а также увеличение площади мышечных трубочек после добавления Актовегина по сравнению с контрольной группой.
Таким образом, результаты исследования свидетельствуют, что ряд компонентов препарата может играть важную роль в регуляции пролиферации мышечных клеток и способствовать улучшению регенерации скелетных мышц. Полученные данные могут объяснять положительное влияние препарата на заживление повреждений мышц, что было показано в предшествующих исследованиях [44].

\section{Б е 3 опас н о сть Актовегина}

Важными особенностями Актовегина являются безопасность его применения и хорошая переносимость, в том числе у пожилых и старых людей с различными сопутствующими заболеваниями. Препарат по сути не имеет какоголибо ожидаемого спектра нежелательных явлений. Побочные эффекты в основном сводятся к аллергическим реакциям, которые возникают редко.

Касаясь вопроса риска развития трансмиссивных заболеваний при использовании Актовегина, необходимо снова подчеркнуть, что специфика производственного процесса исключает возможность попадания прионных частиц в конечную субстанцию [45]. Более того, поставщики телячьей крови проходят процедуру аудита, проводимого компанией на регулярной основе, а ветеринарные сертификаты подтверждают пригодность всех телят для употребления в пищу человеком. Биологическая безопасность используемого сырья в отношении прионных заболеваний была подтверждена сертификатом соответствия Европейского директората по качеству лекарственных средств, при этом установлено, что производство Актовегина удовлетворяет всем требованиям по предотвращению губчатой энцефалопатии, предусмотренным документом Европейского агентства по лекарственным средствам (ЕМА).

Использование препаратов с нейротрофическим эффектом иногда вызывает обеспокоенность практикующих врачей в связи с теоретическим риском стимуляции опухолевого роста. Однако в отношении Актовегина имеются доказательства отсутствия подобного риска. Так, в эксперименте М.Г. Винокурова и соавт. [46] было показано, что в условиях in vitro Актовегин не увеличивает количество опухолевых нейробластомных клеток линии SK-N-S при культивировании в течение 72 ч по сравнению с контролем; более того, препарат в высоких концентрациях снижает их количество, вызывая клеточную гибель.

В заключение следует сказать, что использование нейрометаболических препаратов началось много лет назад эмпирически и долгое время основывалось в большей степени на собственном клиническом опыте, а не на данных исследований. Однако в настоящее время требования доказательной медицины заставляют проводить новые экспериментальные и клинические исследования давно известных лекарственных препаратов. Эти исследования позволяют уже с точки зрения современных научных знаний понять механизмы действия, доказать известную из опыта клиническую эффективность, уточнить место нейрометаболических препаратов в терапии неврологических расстройств, а иногда развеять необоснованные страхи относительно их безопасности и переносимости. 
1. Buchmayer F, Pleiner J, Elminger MW, et al. Actovegin $^{\circledR}$ : a biological drug for more than 5 decades. Wien Med Wochenschr. 2011;161 (3-4):80-8. doi: 10.1007/s10354-011-0865-y 2. Machicao F, Muresanu DF, Hundsberger H, Pflü ger M, Guekht A. Pleiotropic neuroprotective and metabolic effects of Actovegin's mode of action. J Neurol Sci. 2012;322(1):222-7. doi: 10.1016/j.jns.2012.07.069

3. Herrschaft H, Kunze U, Gleim F.

The action of Actovegin on cerebral blood flow and cerebral metabolism in man. Med Welt. 1977;28:339-45.

4. Jager KH, Leybold K, Mittenzwei H, et al. The promotional of cell respiration by a blood extract. Arzneimittel-Forschung / Drug Res. 1965; 15:750-4.

5. De Groot, Brecht M, Machicao F. Evidence for a factor protective against hypoxic liver parenchymal cell injury in a protein-free blood extract. Res Comm Chem Path Pharm. 1990; 68:125-8.

6. Reichel H, Weiss C, Leichtweiss HP. The effects of a blood extract on the oxygen uptake of isolated artificially perfused kidneys and skeletal muscles in rats. Arzneim-Forsch. 1965;15(756):757.

7. Kuninaka T, Senga Y, Senga H, Weiner M. Nature of enhanced mitochondrial oxidative metabolism by a calf blood extract. $J$ Cell Physiol. 1991;146(1):148-55. doi: 10.1002/jcp. 1041460119

8. Bachmann W, Forster H, Mehnert H.

Experimental studies in animals on the effect of a protein-free blood extract on the metabolism of glucose. Arzneimittel-Forschung / Drug Res. 1968;18:1023-7.

9. Parade D, Biro G, Ketti H, et al. Studies on the insulin-like action of a low molecularweight blood extract on the glucose metabolism of isolated isolated tissue of the rat in vitro. Arzneimittel-Forschung / Drug Res. 1968;18: 1019-21.

10. Mohnike G, Lippmann HG, Dieckmann I, et al. Zur Wirkung eines Extraktes aus Kalberblut im Stoffwechsel der Glucose. Arzneimittel-Forschung / Drug Res. 1968;18:1021. 11. Machicao F, Mü hlbacher Ch, Haring HU. Inositol phospho-ooligosaccharides from a dialysate [Actovegin] obtained from blood mimic the effect on lipogenesis glucose transport and lipolysis in rat adipocytes. Aktuelle Endokrinologie und Stoffwechsel. 1989;10(2):111. 12. Machicao F, Sixt B, Seffer E, et al. Adipocytes release inositol phosphate oligosaccharides with insulin like activity similarly as found in hemodialysate. In: IV International Symposium on Insulin Receptor and Insulin Action, Verona, Italy; 1990. P. 124.

13. Machicao F, Mushack J, Seffer E, et al. Mannose, glucosamine and inositol monophosphate inhibit the effects of insulin on lipogenesis. Further evidence for a role for inositol phosphate-oligosaccharides in insulin action. Biochem J. 1990;266:909-16.
14. Jaacob S, Dietze GJ, Machicao F, et al. Improvement of glucose metabolism in patients with type II diabetes after treatment with hemodialysate. Arzneimittelforschung. 1996;(3): 269-72.

15. Dieckmann A, Kriebel M, Andriambeloson E, et al. Treatment with Actovegin improves sensory nerve function and pathology in streptozotocin-diabetic rats via mechanisms involving inhibition of PARP activation. Exp Clin Endocrinol Diabetes. 2011;120(3):132-8. 16. Elmlinger MW, Kriebel M, Ziegler D. Neuroprotective and Anti-Oxidative Effects of the Hemodialysate Actovegin on Primary Rat Neurons in Vitro. Neuromolecular Med. 2011; 13(4):266-74. doi: 10.1007/s12017-011-8157-7 17. Fedorovich AA. Non-invasive evaluation of vasomotor and metabolic functions of microvascular endothelium in human skin. Microvasc Res. 2012;84:86-93. doi: 10.1016/j.mvr.2012.03.011

18. Meilin S, Machicao F, Elmlinger M.

Treatment with Actovegin improves spatial learning and memory in rats following transient forebrain ischaemia. J Cell Mol Med. 2014;18(8): 1623-30. doi: 10.1111/jcmm. 12297

19. Herrmann WM, Bohn-Olszewsky WJ, Kuntz G. Actovegin infusion treatment in patients with primarily degenerative dementia of the Alzheimer type and multi-infarct dementia. Zeitschrift fü r Geriatrie. 1992;5:46-55.

20. Kanowski S, Kinzler E, Lehmann E, et al. Confirmed Clinical Efficacy of Actoveginmin

Elderly Patients with Organic Brain Syndrome.

Pharmacopsychiat. 1995;28:125-33.

doi: $10.1055 / \mathrm{s}-2007-979604$

21. Guekht A, Skoog I, Edmundson S, et al. ARTEMIDA trial (A Randomized Trial of Efficacy, 12 Months International DoubleBlind Actovegin): A Randomized Controlled Trial to Assess the Efficacy of Actovegin in Poststroke Cognitive Impairment. Stroke. 2017;48:1262-70. doi: 10.1161/STROKEAHA. 116.014321

22. Яннсен В, Брукнер ГВ. Лечение хронической цереброваскулярной недостаточности с использованием драже актовегин форте. Русский медицинский журнал. 2002; 10(12):1-4 [Yannsen V, Brukner GV. Treatment of chronic cerebrovascular insufficiency using actotegin forte pills. Russkii Meditsinskii Zhurnal. 2002;10(12):1-4 (In Russ.)].

23. Oswald WD, Steiger W, Oswald B, Kuntz G Die Verbesserung fluider kognitiver leistungen als indikator fuer die klinische Wirksamkeit einer nootropen Substanz. Eine Placebo-kontrollierte Doppelblind-Studie mit Actovegin). Zeitschrifft fur Gerontopsychologie und Psychiatrie. 1991;4:209-20.

24. Saletu B, Gruenberg J, Linzmayer L, et al. EEG Brain Mapping and Psychometry in AgeAssociated Memory Impairment after Acute and 2-Week Infusions with the Gemoderivative Actovegin: Double-Blind, Placebo-Controlled Trials. Neuropsychobiology. 1990;91(24):135-48. doi: $10.1159 / 000119476$
25. Saletu B, Griinberger I, Linzmayer L, Stahr H. Zur Funktionsverbesserung des alternden Gehirns: Plazebokontrollierte PharmaltoEEG und psychometrische Studien mit einem stoffwechselaktiven Hamoderivat (Actovegin). Gerontol. 1984;17:271-9.

26. Semiitsch HV, Anderer P, Saletu B,

Hochmayer I. Topographic mapping of cognitive event-related potentials in a double-blind, placebo-controlled study with the hemoderivative Actovegin in age-associated memory impairment. Neuropsychobiology. 1990-1991; 24:49-56. doi: 10.1159/000119042

27. Федорович АА, Соболева ГН. Коррекция когнитивных нарушений Актовегином у больных артериальной гипертензией и ишемической болезнью сердца. Эффективная фармакотерапия. 2015;23:42-51

[Fedorovich AA, Soboleva GN. Correction of cognitive impairment with Actovegin in patients with arterial hypertension and coronary heart disease. Effektivnaya Farmakoterapiya. 2015; 23:42-51 (In Russ.)].

28. Михайлова НМ, Селезнева НД,

Калын ЯБ и др. Эффективность лечения актовегином больных пожилого возраста с синдромом мягкого когнитивного снижения сосудистого генеза. Журнал неврологии и психиатрии им. С.С. Корсакова. 2013; 7(2):68-75 [Mikhailova NM, Selezneva ND, Kalyn YaB, et al. Efficacy of treatment with aktovegin elderly patients with mild cognitive decline syndrome of vascular genesis. Zhurnal Nevrologii i Psikhiatrii im. S.S. Korsakova. 2013; 7(2):68-75 (In Russ.)].

29. Остроумова ОД. Коррекция когнитивных нарушений Актовегином у больных гипертонической болезнью. Медицинский алфавит. 2012;(4):4-8 [Ostroumova OD.

Correction of cognitive impairment with Actovegin in patients with essential hypertension. Meditsinskii Alfavit. 2012;(4):4-8 (In Russ.)]. 30. Захаров ВВ, Сосина ВБ. Возможности антигипоксантов в лечении умеренных когнитивных нарушений у больных сахарным диабетом. Лечащий врач. 2010;(3):87-91 [Zakharov VV, Sosina VB. Possibilities of antihypoxic drugs in the treatment of moderate cognitive impairment in patients with diabetes mellitus. Lechashchii Vrach. 2010;(3):87-91 (In Russ.)].

31. Ziegler D, Movsesyan L, Mankovsky B, et al. Treatment of symptomatic polyneuropathy with actovegin in type 2 diabetic patients. Diabetes Care. 2009;32(8):1479-84. doi: 10.2337/dc090545

32. Моргоева ФЭ, Аметов АС, Строков ИА. Диабетическая энцефалопатия и полиневропатия: терапевтические возможности Актовегина. Русский медицинский журнал. 2005;(6):302-6 [Morgoeva FE, Ametov AS, Strokov IA. Diabetic encephalopathy and polyneuropathy: Actovegin's therapeutic potential. Russkii Meditsinskii Zhurnal. 2005;(6): 302-6 (In Russ.)]. 
33. Horsch S, Claeys L, Diehm C, et al. [Assessment of the clinical effectiveness of actihaemyl in Fontaine stage IIb intermittent claudication]. Vasa Suppl. 1992;37:64-5.

34. Angelkort B, Ruhlmann KU, de la Haye R, et al. Influence of deproteinized hemodialysate on rest pain and walking distance in the presence of peripheral chronic arterial occlusive disease. Angiology. 1992;43:47-58. doi: 10.1177/ 000331979204300106

35. Учкин ИГ, Зудин АМ, Багдасарян АГ, Федорович АА. Влияние фармакотерапии хронических облитерирующих заболеваний артерий нижних конечностей на состояние микроциркуляторного русла. Ангиология и сосудистая хирургия. 2014;20(2):27-36 [Uchkin IG, Zudin AM, Bagdasaryan AG, Fedorovich AA. The effect of pharmacotherapy of chronic obliterating diseases of lower limb arteries on the state of the microvasculature. Angiologiya i Sosudistaya Khirurgiya. 2014; 20(2):27-36 (In Russ.)].

36. Stein R, Seuser J. Local use of Actovegin ampoule solution in crural ulcer. Med Welt. 1986;37:173-6.

37. Учкин ИГ, Мосесов АГ, Цырульников АА. Актовегин как компонент комплексной терапии осложненных форм хронической венозной недостаточности нижних конечностей. Русский медицинский журнал. 2007; 12(15):981-5 [Uchkin IG, Mosesov AG,
Tsyrul'nikov AA. Actovegin as a component of the complex therapy of complicated forms of chronic venous insufficiency of the lower extremities. Russkii Meditsinskii Zhurnal. 2007; 12(15):981-5 (In Russ.)].

38. Хисматов РР, Трухова ВВ, Макарова НН, Гусева СЛ. Актовегин в лечении трофических язв нижних конечностей венозной этиологии. Русский медицинский журнал. 2008;30(16):2022-4 [Khismatov RR, Trukhova VV, Makarova NN, Guseva SL. Actovegin in the treatment of trophic ulcers of the lower extremities of venous etiology. Russkii Meditsinskii Zhurnal. 2008;30(16):2022-4 (In Russ.)]. 39. https://clinicaltrials.gov/ct2/show/ NCT03469349?term $=$ Actovegin\&rank $=1$ 40. Sondergard SD, Dela F, Helge JW, Larsen S. Actovegin, a nonprohibited drug increases oxidative capacity in human skeletal muscle. Eur J Sport Sci. 2016;16:801-7. doi: 10.1080/ 17461391.2015.1130750

41. Lee P, Rattenberry A, Connelly S, Nokes L. Our experience on Actovegin, is it cutting edge? Int J Sports Med. 2011;32:237-41. doi: 10.1055/ s-0030-1269862

42. WADA. Список запрещенных препаратов (2017 г.). Доступно по ссылке: https://www.wadaama.org/en/media/news/201 6-09/wadapublishes-2017-prohibited-list [WADA, List of prohibited drugs (2017). Available by reference: https://www.wadaama.org/en/media/news/201 6-09/wadapublishes-2017-prohibited-list]. 43. Reichl FY, Holdt LM, Teupser D, et al. Comprehensive analytics of Actovegin ${ }^{\circledast}$ and its effect on muscle cells. Int J Sports Med. 2017; 38:809-18. doi: 10.1055/s-0043-115738 44. Pforringer W, Pfister A, Kuntz G.

The treatment of Achilles paratendinitis: results of a double-blind, placebo-controlled study with a deproteinized hemodialysate. Clin J Sport Med. 1994;4:92-9. doi: 10.1097/00042752199404000-00005

45. Бойченко МН, Волчкова ЕВ, Пак СГ. Биопрепараты и прионные болезни, возможна ли этиологическая связь? Фарматека. 2012;s3-12:47-54 [Boichenko MN,

Volchkova EV, Pak SG. Biopreparations and prion diseases, is etiological connection possible? Farmateka. 2012;s3-12:47-54 (In Russ.)]. 46. Винокуров МГ, Юринская ММ, Князев АВ, Асташкин ЕИ. Влияние гемодеривата крови телят на жизнеспособность, апоптоз и некроз клеток нейробластомы человека SK-N-SH. Экспериментальная и клиническая фармакология. 2017;80(3):31-5 [Vinokurov MG, Yurinskaya MM, Knyazev AV, Astashkin EI. Effect of calf blood hemoderivate on viability, apoptosis and necrosis of human neuroblastoma cells SK-N-SH. Eksperimental'naya i Klinicheskaya Farmakologiya. 2017; 80(3):31-5 (In Russ.)].

\section{Поступила 20.03.2019}

Публикация статьи поддержана ООО «Такеда Фармасьютикалс». Авторы несут полную ответственность за предоставление окончательной версии рукописи в печать. Все авторы принимали участие в разработке концепции статьи и написании рукописи. Окончательная версия рукописи была одобрена всеми авторами. 